\title{
Long non-coding RNA GAS5 inhibits cell proliferation, induces G0/G1 arrest and apoptosis, and functions as a prognostic marker in colorectal cancer
}

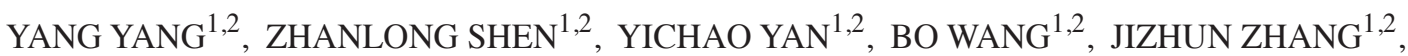 \\ CHAO SHEN $^{1,2}$, TAO LI $^{1,2}$, CHUNXIANG YE $^{1,2}$, ZHIDONG GAO $^{1,2}$, GUO PENG $^{1,2}$, \\ YINGJIANG YE $^{1,2}$, KEWEI JIANG ${ }^{1,2}$ and SHAN WANG ${ }^{1,2}$ \\ ${ }^{1}$ Department of Gastroenterological Surgery; ${ }^{2}$ Laboratory of Surgical Oncology, \\ Peking University People's Hospital, Beijing 100034, P.R. China
}

Received July 5, 2016; Accepted October 27, 2016

DOI: $10.3892 / 01.2017 .5841$

\begin{abstract}
Colorectal cancer (CRC) is the third most common cancer worldwide and its treatment remains a challenge. Effective control of cell survival and proliferation is critical in the prevention of oncogenesis and successful treatment of cancer. Long non-coding RNAs (lncRNAs) have emerged as primary regulators of carcinogenesis. Growth arrest specific 5 (GAS5), a lncRNA, is known to be aberrantly expressed in several types of cancer, however, the role of GAS5 in CRC remains unclear. In the present study, GAS5 mRNA expression was measured in CRC and adjacent normal mucosa tissue samples from 53 patients using reverse transcription-quantitative polymerase chain reaction analysis, in addition to seven CRC cell lines. GAS5 mRNA expression was observed to be markedly downregulated in human CRC tissues and cell lines. Decreased GAS5 expression was associated with an increase in tumor diameter [odds ratio (OR), 0.176 (95\% CI, 0.053-0.586); $\mathrm{P}=0.003$ ] and later tumor-node-metastasis stage [OR, 0.261 (95\% CI, 0.083-0.819); $\mathrm{P}=0.019$ ]. Patients with decreased GAS5 expression exhibited decreased overall survival rates compared with patients with increased GAS5 expression $(\mathrm{P}=0.015)$. The Cox proportional hazards model demonstrated that downregulated GAS5 expression was an independent prognostic factor for CRC (hazard ratio, 0.236; 95\% confidence interval, 0.067-0.827; $\mathrm{P}=0.024)$. Functional assays demonstrated that overexpression of GAS5 inhibited cell proliferation and survival, and induced G0/G1 cell cycle
\end{abstract}

Correspondence to: Professor Kewei Jiang or Professor Shan Wang, Department of Gastroenterological Surgery, Peking University People's Hospital, 11 Xizhimen South Street, Beijing 100034, P.R. China

E-mail: dr_jiangkewei@163.com

E-mail: shanwang60@sina.com

Key words: colorectal cancer, prognosis, long non-coding RNA, growth arrest specific 5 , proliferation arrest and apoptosis; however, knockdown of GAS5 expression enhanced cell proliferation, and reduced G0/G1 arrest and apoptosis. In conclusion, the results of the present study suggest that GAS5 is essential in the control of apoptosis and cell growth in CRC. Therefore, GAS5 may represent a novel prognostic and diagnostic marker of $\mathrm{CRC}$, in addition to being a potential therapeutic target.

\section{Introduction}

Colorectal cancer (CRC) is the third most common cancer in men, the second most common cancer in women and the fourth-leading cause of cancer-associated mortality worldwide (1). CRC morbidity and mortality has increased in recent years (2). Although advancements in treatment have been made, the identification of new prognostic biomarkers and improving the understanding of the molecular mechanisms underlying CRC remains a challenge (3). Therefore, investigating the mechanisms underlying the occurrence and development of $\mathrm{CRC}$, and identifying novel diagnostic biomarkers and effective therapeutics is of high importance $(4,5)$.

Long non-coding RNAs (lncRNAs) are RNA transcripts of $>200$ nucleotides in length that are located in the nucleus and cytosol, and are often expressed in a disease-, tissue- or developmental stage-specific manner (6). Previous studies have demonstrated that lncRNAs serve important roles in transcriptional regulation, cell growth, carcinogenesis and metastasis $(7,8)$. Aberrant expression of lncRNAs has been observed in CRC and may have an oncogenic or tumor suppressive role in the cancer initiatome $(8,9)$. Growth arrest specific 5 (GAS5) is a lncRNA that is associated with cell proliferation, and serves an essential role in the growth arrest of T-cells and non-transformed lymphocytes (10). Overexpression of GAS5 decreases the rate of cell cycling, whereas downregulation of GAS5 inhibits apoptosis and maintains faster cell cycle progression. Mourtada-Maarabouni et al (11) demonstrated that GAS5 transcription levels were significantly decreased in breast cancer samples compared with adjacent healthy breast epithelial tissue. Inhibition of cell growth and induction of apoptosis through GAS5 overexpression was independent of 
other stimuli in certain cell lines (11). However, the role of GAS5 in CRC remains to be completely elucidated.

To clarify the clinical significance of GAS5 expression in CRC, GAS5 expression in CRC tissues and cell lines was investigated, and the association between GAS5 expression in tumor tissue and patient outcome was analyzed. To further understand the functional significance of GAS5, the effect of altered GAS5 levels on the phenotype of CRC cells was examined. The results of the present study demonstrated that GAS5 expression is frequently decreased in CRC, indicating that GAS5 serves an essential role in the suppression of CRC and is a predictor of poor survival in patients with CRC. The present study demonstrates the importance of developing lncRNA-directed diagnostic and therapeutic agents.

\section{Materials and methods}

Tissue collection. A total of 53 CRC tissue samples and the adjacent normal tissues were obtained from patients diagnosed with CRC following histopathological evaluation between January 2010 and May 2010, according to the seventh edition of the American Joint Committee on Cancer Staging Manual (12). The patients whose clinicopathological data was incomplete or whose total RNA following extraction was degraded were excluded. Patients underwent surgery at Peking University People's Hospital (Beijing, China) and clinicopathological information was recorded for all samples (Table I). No local or systemic treatment was given to patients prior to CRC tissue sample excision. All specimens were immediately frozen in liquid nitrogen and stored at $-80^{\circ} \mathrm{C}$ until required for RNA extraction. The present study was approved by the Research Ethics Committee of Peking University (Beijing, China). Informed consent was obtained from all patients.

Cell lines and culture conditions. A total of seven human CRC cell lines (SW480, SW620, RKO, HCT116, HT-29, LoVo and LS174T) were purchased from the American Type Culture Collection (Manassas, VA, USA). The wild-type human colon mucosal epithelial cell line, NCM460, was purchased from INCELL Corporation LLC (San Antonio, TX, USA). SW480 and SW620 cells were cultured in Leibovitz's L-15 medium, while the other cell lines were cultured in RPMI-1640 medium, both supplemented with $10 \%$ fetal bovine serum (FBS) (all Gibco; Thermo Fisher Scientific, Inc., Waltham, MA, USA), $100 \mathrm{IU} / \mathrm{ml}$ penicillin and $100 \mathrm{mg} / \mathrm{ml}$ streptomycin. Cells were incubated at $37^{\circ} \mathrm{C}$ with $5 \% \mathrm{CO}_{2}$.

Total RNA extraction and reverse transcription-quantitative polymerase chain reaction $(R T-q P C R)$ analysis. Total RNA was extracted from tissue samples/cultured cells using TRIzol ${ }^{\circledR}$ reagent (Invitrogen; Thermo Fisher Scientific, Inc.). cDNA was synthesized from RNA via reverse transcription using the PrimeScript RT 5X Master Mix (cat no. RR036A; Takara Biotechnology Co., Ltd., Dalian, China). qPCR was performed using the SYBR ${ }^{\circledR}$ Green I Premix Ex Taq ${ }^{\mathrm{TM}}$ II master mix (cat. no. RR820A; Takara Biotechnology Co., Ltd.) according to the manufacturer's protocol. cDNA (50 ng) was used and the thermocycling conditions were as follows: $30 \mathrm{sec}$ at $95^{\circ} \mathrm{C}$; then $95^{\circ} \mathrm{C}$ for $5 \mathrm{sec}$; and $60^{\circ} \mathrm{C}$ for $30 \mathrm{sec}$ for 40 cycles. Results were normalized to the expression of
GAPDH. PCR primer sequences for GAS5 and GAPDH were as follows: GAS5 forward, 5'-CTTCTGGGCTCAAGT GATCCT-3' and reverse, 5'-TTGTGCCATGAGACTCCA TCAG-3'; and GAPDH forward, 5'-GTCAACGGATTTGGT CTGTATT-3' and reverse, 5'-AGTCTTCTGGGTGGCAGT GAT-3'. RT-qPCR and data collection was performed using an $\mathrm{ABI}^{\circledR} 7500$ Real-Time PCR System running version 2.07500 software (Applied Biosystems; Thermo fisher Scientific, Inc.). GAS5 expression was calculated and subsequently normalized to the expression of GAPDH in SW480, SW620, RKO, HCT116, HT-29, LoVo and LS174T and NCM460 cells using the $2^{-\Delta \Delta \mathrm{Cq}}$ method (13).

GAS5 overexpression, knockdown and transfection. The full-length GAS5 sequence (National Center for Biotechnology Information code, NR_002578) synthesized by PCR was purchased and cloned into a pCDNA3.1(+) vector with NheI and BamHI sites (both Invitrogen; Thermo fisher Scientific, Inc.) to produce pCDNA-GAS5. An empty pCDNA3.1(+) vector was used as the vehicle control. Small interfering RNAs (siRNAs) targeting human GAS5 mRNA (si-h-GAS5) and the negative control siRNA (cat no. siN05815122147) were purchased from Guangzhou RiboBio Co., Ltd. (Guangzhou, China). The sequences of the anti-GAS5 siRNAs were as follows: si-1, CTTGCCTGGACCAGCTTAA; si-2, GCA AGCCTAACTCAAGCCA; si-3, GCAAAGGACTCAGAA TTCA. Transfections with $50 \mathrm{nM}$ pCDNA-GAS5, empty vector, siRNA-h-GAS5 or NC siRNA were performed using Lipofectamine ${ }^{\circledR} 2000$ (Invitrogen; Thermo fisher Scientific, Inc.) according to the manufacturer's protocol and cells were harvested following a $72 \mathrm{~h}$ incubation at $37^{\circ} \mathrm{C}$ with $5 \% \mathrm{CO}_{2}$. For functional analysis of GAS5, pCDNA-GAS5 was transfected into SW480 and HCT-116 cells, and siRNA-h-GAS5 was transfected into RKO cells.

Analysis of apoptosis and cell cycle progression. A total of $2 \times 10^{5}$ cells were seeded into 12 -well plates 1 day prior to transfection and cells were harvested $72 \mathrm{~h}$ following transfection. Apoptotic cells were analyzed using the Alexa FluorR ${ }^{\circledR}$ 488 Annexin V/Dead Cell Apoptosis kit (Invitrogen; Thermo fisher Scientific, Inc.) according to the manufacturer's protocol. To assay the number of cells in each stage of the cell cycle, cells were harvested and subsequently stained using the BD Cycletest $^{\mathrm{TM}}$ Plus DNA Reagent kit (BD Biosciences, Franklin Lakes, NJ, USA), according to the manufacturer's instructions. Cells were then detected using flow cytometry and data analyzed using FlowJo software (version 7; Tree Star, Inc., Ashland, OR, USA).

Cell proliferation and colony formation assays. SW480, HCT-116 and RKO cells $\left(2 \times 10^{5}\right)$ were seeded into 12 -well plates day prior to transfection and cells were harvested $72 \mathrm{~h}$ following transfection. Cell proliferation assays were performed over the next 24-120 h using the Cell Counting Kit-8 (CCK8; Sigma-Aldrich; Merck Millipore, Darmstadt, Germany), according to the manufacturer's instructions. For the colony formation assay, SW480, HCT-116 and RKO cells were plated into 6-well plates at a density of 500 cells/well, and maintained in media containing $10 \%$ FBS for 10 days at $37^{\circ} \mathrm{C}$ with $5 \% \mathrm{CO}_{2}$. Colonies were then fixed with methanol 

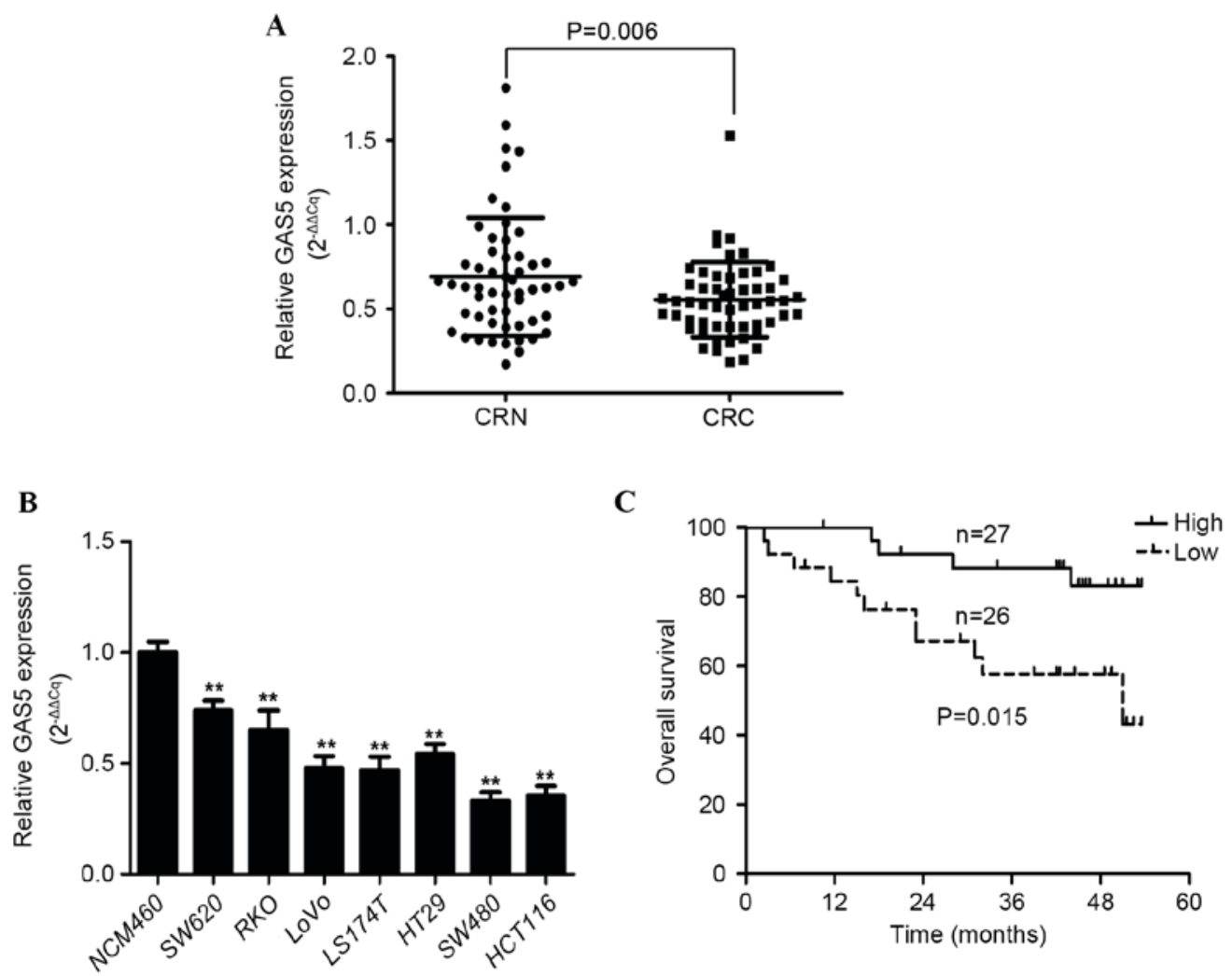

Figure 1. GAS5 mRNA expression in cancerous and normal colorectal tissues and cell lines, and its association with overall survival. (A) GAS5 mRNA expression (normalized to GADPH) in CRC tissues compared with CRN tissue samples ( $\mathrm{n}=53$ ). (B) GAS5 mRNA expression in CRC cell lines compared with the wild-type colorectal cell line NCM460. ${ }^{* *} \mathrm{P}<0.01$. (C) Kaplan-Meier estimator curves of overall survival rates in patients with CRC according to high or low GAS5 mRNA expression levels. GAS5, growth arrest specific 5; CRC, colorectal cancer tissue sample; CRN, corresponding wild-type tissue sample.

and stained using $0.1 \%$ crystal violet (Sigma-Aldrich; Merck Millipore). Visible colonies were manually counted. The colony assay was repeated three times in duplicate.

Statistical analysis. Statistical analysis was performed using SPSS software (version 20.0; SPSS Inc., Chicago, IL, USA). Values are presented as the mean \pm standard deviation. Statistical differences between groups were analyzed using the Student's $t$-test. The association between GAS5 expression and the clinicopathological features of CRC was analyzed using the Chi-squared test. The difference in GAS5 expression between CRC tissue and adjacent normal tissue was analyzed using a Student's $t$-test. Survival analysis was performed using the Kaplan-Meier estimator. The log-rank test was used to analyze differences between the high and low GAS5 expression groups. A Cox proportional hazards analysis was performed to evaluate the independent prognostic factors of overall survival (OS) in patients with CRC. $\mathrm{P}<0.05$ was considered to indicate a statistically significant difference.

\section{Results}

Expression of GAS5 is downregulated in human CRC tissues and cell lines. GAS5 expression was examined in CRC tissue samples and adjacent histologically normal tissue samples from 53 patients using RT-qPCR, with results normalized to GAPDH. GAS5 expression was significantly decreased in
CRC tissue samples compared with the adjacent healthy tissue by a median relative expression difference of $0.2568 \pm 0.6722$ ( $\mathrm{P}=0.006$; Fig. 1A). The median ratio between relative GAS5 expression in cancerous tissue compared with normal tissue was 0.532 (Fig. 1A). GAS5 expression was downregulated in $35 / 53$ (66\%) CRC tissue samples compared with the corresponding adjacent healthy tissue. In addition, the relative expression level of GAS5 in the CRC cell lines (SW480, SW620, RKO, LOVO, LS174T, HT-29 and HCT116) was significantly decreased compared with the normal colorectal mucosa cell line (NCM460) $(\mathrm{P}<0.001, \mathrm{P}=0.003, \mathrm{P}=0.004, \mathrm{P}<0.001$, $\mathrm{P}<0.001, \mathrm{P}=0.003$ and $\mathrm{P}<0.001$, respectively; Fig. 1B). These results indicate that abnormal GAS5 expression is associated with CRC tumorigenesis and pathogenesis.

Association between GAS5 expression and clinicopathological features in patients with CRC. The clinicopathological characteristics of 53 patients with colorectal carcinoma are presented in Table I. According to the median ratio of GAS5 mRNA expression in CRC tissue compared with adjacent healthy tissue (0.532), the 53 patients with CRC were classified into two groups, high GAS5 expression $(\mathrm{n}=27$; relative GAS5 expression $\geq 0.532)$ and low GAS5 expression $(n=26$; relative GAS5 expression <0.532) (Table II). Follow-ups demonstrated that the low GAS5 expression group exhibited a significantly increased tumor size [odds ratio (OR), 0.176; 95\% CI, 0.053-0.586; $\mathrm{P}=0.003$ ) and more advanced 
tumor-node-metastasis (TNM) stage (OR, 0.261; 95\% CI, 0.083-0.819; $\mathrm{P}=0.019$ ) (Table II). No significant differences were observed in the distribution of gender, age, histological differentiation, depth of invasion, lymphatic metastasis, regional lymph node status or presence of distant metastasis between patients in the high and low GAS5 mRNA expression groups (Tables I and II).

Decreased GAS5 mRNA expression is a predictor of poor prognosis in patients with CRC. The correlation between GAS5 expression and the outcome of patients with CRC following a colectomy was examined. OS curves of patients were plotted according to high or low GAS5 expression status using the Kaplan-Meier estimator. As shown in Fig. 1C, patients expressing low levels of GAS5 mRNA had a significantly shorter median survival time (37.8 \pm 3.8 months) compared with patients expressing high levels of GAS5 (49.2 \pm 2.1 months) $(\mathrm{P}=0.015)$. These results suggest that downregulated GAS5 expression is significantly associated with poor OS in patients with CRC.

The Cox proportional hazards model demonstrated that the level of GAS5 mRNA expression [hazard ratio (HR), 0.236; 95\% confidence interval (CI), 0.067-0.827; $\mathrm{P}=0.024]$, TNM stage (HR, 0.164; 95\% CI, 0.032-0.754; $\mathrm{P}=0.010$ ) and distant metastasis status (HR, 0.089; 95\% CI, 0.025-0.317; $\mathrm{P}<0.001$ ) were significantly associated with the OS rate of patients with $\mathrm{CRC}$, and may be used as independent prognostic factors (Table III). These results indicate that a low GAS5 expression level is an independent risk factor for CRC and a predictor of poor prognosis.

GAS5 decreases CRC cell growth and colony formation, and induces G0/G1 cell cycle arrest and apoptosis. The role of GAS5 in CRC pathology was functionally analyzed in vitro through the overexpression or knockdown of GAS5 in CRC cell lines. SW480 and HCT116 cells were transfected with pCDNA3.1-GAS5 in order to induce GAS5 overexpression, and RKO cells were transfected with siRNA-h-GAS5 in order to knockdown GAS5. GAS5 mRNA overexpression and knockdown was confirmed using RT-qPCR (Fig. 2A and B). CCK-8 analysis demonstrated that GAS5 overexpression significantly repressed the rate of cell proliferation in the SW480 and HCT116 cell lines, whereas knockdown of GAS5 increased proliferation in siRNA-h-GAS5-transfected RKO cells (Fig. 2C). Furthermore, a colony formation assay revealed that clonogenic survival was significantly decreased in SW480 and HCT116 cells transfected with pCDNA3.1-GAS5 compared with the negative control group $(\mathrm{P}<0.001$; Fig. 2D); however, the opposite phenomenon was observed in siRNA-h-GAS5-transfected RKO cells ( $\mathrm{P}=0.001$; Fig. 2D).

The inhibitory effect of GAS5 on cell cycle progression and apoptosis was examined using flow cytometry. Compared with their respective controls, upregulation of GAS5 expression resulted in the accumulation of G0/G1 cells in the SW480 (52.83 $\pm 3.16 \%$ vs. $61.58 \pm 3.47 \% ; \mathrm{P}=0.032)$ and HCT116 $(53.88 \pm 3.82 \%$ vs. $63.95 \pm 2.97 \% ; \mathrm{P}=0.022)$ cell lines, whereas downregulation of GAS5 expression reduced the number of G0/G1 cells in the siRNA-h-GAS5-transfected RKO cells $(66.22 \pm 1.24 \%$ vs. $56.42 \pm 2.30 \% ; \mathrm{P}=0.020$ vs. the control) (Fig. 2E). In addition, the rate of apoptosis was significantly
Table I. Clinicopathological characteristics of 53 patients with colorectal carcinoma.

\begin{tabular}{lc}
\hline Clinicopathological parameter & Number of patients (\%) \\
\hline Gender & \\
Male & $35(66.0)$ \\
Female & $18(34.0)$ \\
Age (years) & \\
$<60$ & $15(34.0)$ \\
$>60$ & $38(66.0)$ \\
Tumor size (cm) & \\
$<2$ & $23(43.4)$ \\
$>2$ & $30(56.7)$ \\
Histological differentiation & \\
Well & $2(3.8)$ \\
Moderate & $42(79.2)$ \\
Poor & $9(17.0)$ \\
Depth of invasion & \\
T1+T2 & $5(9.4)$ \\
T3+T4 & $48(90.6)$ \\
TNM stage & \\
I+II & $25(47.2)$ \\
III+IV & $28(52.8)$ \\
Lymphatic metastasis & \\
Yes & $25(47.2)$ \\
No & $28(52.8)$ \\
Regional lymph nodes & \\
pN0 & \\
pN1 & $28(52.8)$ \\
pN2 & $16(30.2)$ \\
pNX & $8(15.1)$ \\
Distant metastasis & $1(1.9)$ \\
Yes & \\
No & $9(17.0)$ \\
Expression of GAS5 & \\
High & $27(83.0)$ \\
Low & \\
& \\
& \\
&
\end{tabular}

T, tumor stage; TNM, tumor-node-metastasis stage; $\mathrm{pN}$, pathological assessment of regional lymph nodes; GAS5, growth arrest specific 5.

increased following ectopic expression of GAS5 in SW480 $(13.37 \pm 0.54 \%$ vs. $21.89 \pm 0.85 \%)$ and HTC116 $(9.92 \pm 0.56 \%$ vs. $16.33 \pm 0.85 \%$ ) cells (both $\mathrm{P}<0.001$; Fig. $2 \mathrm{~F}$ ), but decreased in siRNA-h-GAS5-transfected RKO cells $(16.19 \pm 0.32 \%$ vs. $7.08 \pm 1.02 \%)$; $(\mathrm{P}<0.001$ vs. the control group; Fig. $2 \mathrm{~F})$. These results suggest that GAS5 inhibits CRC cell growth and colony formation, and induces $\mathrm{G} 0 / \mathrm{G} 1$ arrest and apoptosis.

\section{Discussion}

The cancer transcriptome is more complex than was previously expected $(14,15)$. Although initially thought to be spurious 
Table II. Correlation between GAS5 mRNA expression and clinicopathological characteristics in patients with colorectal carcinoma.

\begin{tabular}{|c|c|c|c|}
\hline \multirow[b]{2}{*}{$\begin{array}{l}\text { Clinicopathological } \\
\text { parameter }\end{array}$} & \multicolumn{2}{|c|}{ GAS5 mRNA expression group } & \multirow[b]{2}{*}{$\begin{array}{l}\text { Chi-squared } \\
\text { test P-value }\end{array}$} \\
\hline & $\begin{array}{l}\text { High (number } \\
\text { of patients) }\end{array}$ & $\begin{array}{l}\text { Low (number } \\
\text { of patients) }\end{array}$ & \\
\hline \multicolumn{4}{|l|}{ Sex } \\
\hline Male & 15 & 20 & 0.101 \\
\hline Female & 12 & 6 & \\
\hline \multicolumn{4}{|l|}{ Age } \\
\hline$<60$ & 7 & 8 & 0.696 \\
\hline$>60$ & 20 & 18 & \\
\hline \multicolumn{4}{|l|}{ Tumor size (cm) } \\
\hline$<2$ & 17 & 6 & $0.003^{\mathrm{a}}$ \\
\hline$>2$ & 10 & 20 & \\
\hline \multicolumn{4}{|c|}{ Histological differentiation } \\
\hline Well & 0 & 2 & 0.492 \\
\hline Moderate & 22 & 20 & \\
\hline Poor & 5 & 4 & \\
\hline \multicolumn{4}{|l|}{ Depth of invasion } \\
\hline $\mathrm{T} 1+\mathrm{T} 2$ & 4 & 1 & 0.370 \\
\hline $\mathrm{T} 3+\mathrm{T} 4$ & 23 & 25 & \\
\hline \multicolumn{4}{|l|}{ TNM stage } \\
\hline $\mathrm{I}+\mathrm{II}$ & 17 & 8 & $0.019^{\mathrm{a}}$ \\
\hline III+IV & 10 & 18 & \\
\hline \multicolumn{4}{|l|}{ Lymphatic metastasis } \\
\hline Yes & 14 & 11 & 0.487 \\
\hline No & 13 & 15 & \\
\hline \multicolumn{4}{|l|}{ Regional lymph nodes } \\
\hline $\mathrm{pN} 0$ & 13 & 15 & 0.771 \\
\hline $\mathrm{pN} 1$ & 8 & 8 & \\
\hline $\mathrm{pN} 2$ & 4 & 4 & \\
\hline $\mathrm{pNX}$ & 1 & 0 & \\
\hline \multicolumn{4}{|l|}{ Distant metastasis } \\
\hline Yes & 3 & 6 & 0.427 \\
\hline No & 24 & 20 & \\
\hline
\end{tabular}

${ }^{\mathrm{a}} \mathrm{P}<0.05$. T, tumor stage; TNM, tumor-node-metastasis stage; $\mathrm{pN}$, pathological assessment of regional lymph nodes; GAS5, growth arrest specific 5 .

transcriptional noise, lncR NAs are now known to participate in the regulation of cellular development, cell growth and the development of human disease, including cancer (16-19). A number of lncRNAs serve important regulatory roles in chromosome modification (20), transcription in the nucleus and post-transcriptional processing in the cytoplasm (21). Accumulating evidence has demonstrated that lncRNA dysregulation affects epigenetic regulation and induces cell growth, resulting in progressive and uncontrolled tumor growth $(8,20,22-26)$. The lncRNA GAS5 is non-coding, hosts multiple small nucleolar (sno) RNA sequences in its introns and contains 12 exons $(27,28)$. GAS5 was initially identified during screening for potential tumor suppressor genes (29) and is a stress-inducible gene, which is differentially expressed in healthy and tumor tissues/cell lines (30). In addition, GAS5 has been demonstrated to be involved in the regulation of the cell cycle (31) and to function as a tumor suppressor in human $\mathrm{T}$ cells, and breast and prostate cancer cell lines by inducing apoptosis $(10,11,32,33)$. Furthermore, reduced expression of GAS5 and/or its snoRNAs has been observed in head and neck squamous cell carcinomas, and gastric and cervical cancer (34-36), indicating that it serves an important role in tumorigenesis.

However, the underlying mechanisms behind the effects of GAS5 in CRC remain unclear. In the present study, the clinical and prognostic significance of GAS5 in 53 patients 

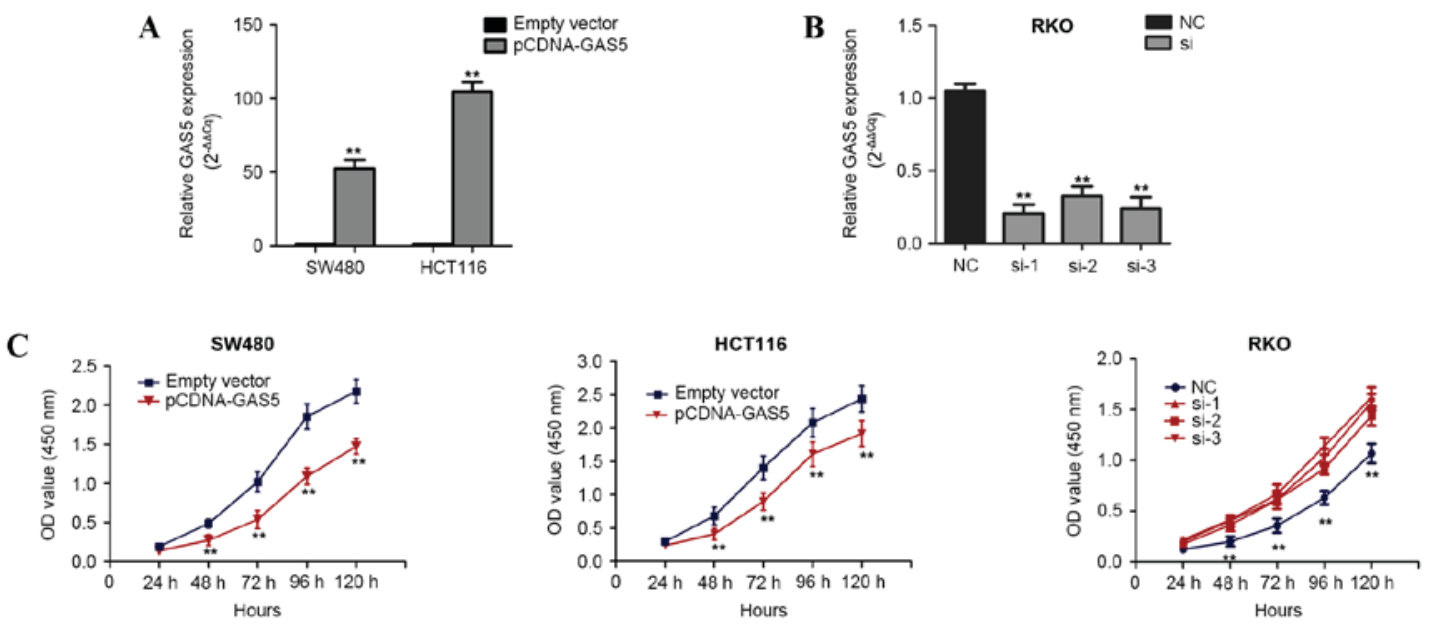

D
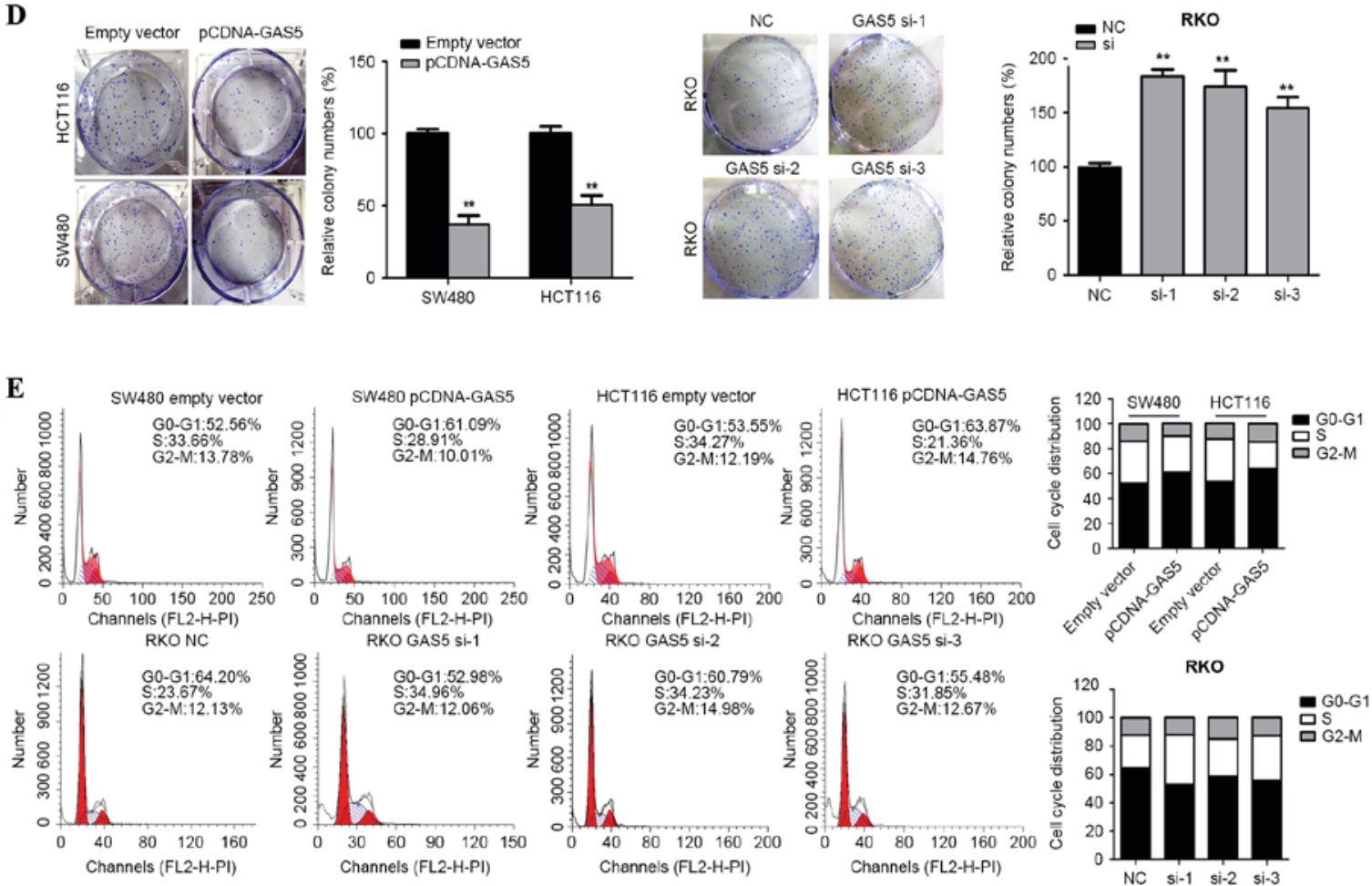

$\mathbf{F}$
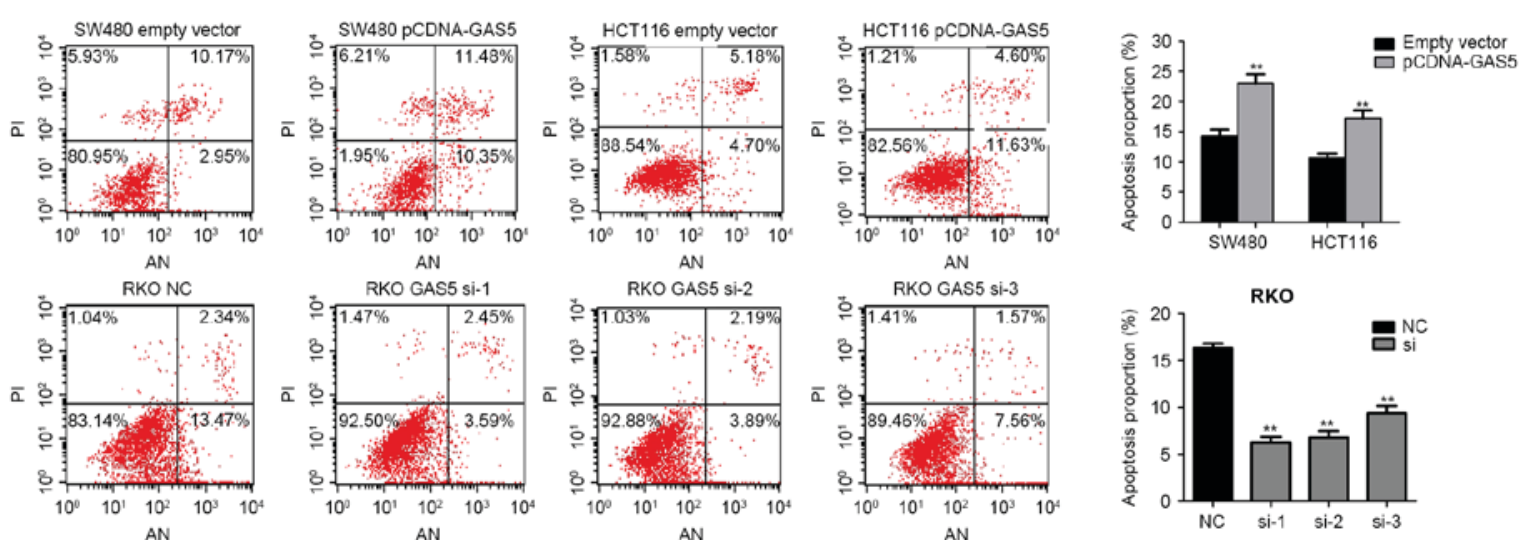

Figure 2. Role of GAS5 as a tumor suppressor in colorectal cancer cell lines. (A) GAS5 mRNA expression (normalized to GADPH) following transfection with pCDNA-GAS5 in the SW480 and HCT116 cell lines, compared with empty vector-transfected cells. (B) GAS5 mRNA expression following transfection with siGAS5 in the RKO cell line compared with transfection with the NC siRNA. Normalized to GAPDH. (C) Effect of transient transfection with $50 \mathrm{nM}$ pCDNA-GAS5, empty vector, siRNA-h-GAS5 or NC siRNA on the proliferation of SW480, HCT116 and RKO cells. (D) Effect of upregulation and knockdown of GAS5 expression on colony formation. Flow cytometric analysis of GAS5-induced (E) cell cycle arrest and (F) apoptosis. ${ }^{* *} \mathrm{P}<0.01$ vs. empty vector (SW480 and HCT116 cells) or NC siRNA (RKO cells). Values are presented as mean \pm standard deviation of 3 independent experiments. GAS5, growth arrest specific 5; si, small interfering RNA; NC, negative control; PI, propidium iodide; AN, annexin V. 
Table III. Cox proportional hazards model of variables associated with overall survival in patients with colorectal carcinoma $(n=53)$.

Multivariate analysis

\begin{tabular}{lll}
\cline { 2 - 2 } Variables & HR $(95 \%$ CI $)$ & P-value \\
\hline Age (<60 vs. $\geq 60$ years old) & $0.996(0.954-1.041)$ & 0.996 \\
Sex (males vs. females) & $0.805(0.231-2.806)$ & 0.805 \\
Tumor size $(<2$ vs. $\geq 2 \mathrm{~cm})$ & $0.489(0.193-2.179)$ & 0.484 \\
Histological differentiation & $0.366(0.100-1.339)$ & 0.129 \\
(well and moderate differentiation & \\
vs. poor differentiation) & & \\
TNM stage (I+II vs. III+IV) & $0.164(0.032-0.754)$ & $0.010^{\mathrm{a}}$ \\
Depth of invasion (T1+T2 vs. T3+T4) & $2.258(0.202-25.235)$ & 0.508 \\
Lymphatic metastasis (present vs. absent) & $0.506(0.159-1.611)$ & 0.249 \\
Distant metastasis (present vs. absent) & $0.089(0.025-0.317)$ & $0.000^{\mathrm{a}}$ \\
GAS5 mRNA expression (high vs. low) & $0.236(0.067-0.827)$ & $0.024^{\mathrm{a}}$ \\
\hline
\end{tabular}

${ }^{a} \mathrm{P}<0.05$ obtained by Cox proportional hazards analysis. HR, hazard ratio; CI, confidence interval; TNM, tumor-node-metastasis stage; GAS5, growth arrest specific 5 .

with CRC was investigated. Analysis of GAS5 mRNA expression using RT-qPCR demonstrated that GAS5 was significantly downregulated in CRC tissue samples compared with adjacent normal tissue. Decreased GAS5 expression was also identified in several CRC cell lines compared with a wild-type colorectal mucosa cell line. In addition, the present study revealed that decreased GAS5 expression was associated with increased tumor size and an increased TNM stage. Furthermore, downregulated GAS5 expression was associated with poor prognosis in patients with CRC. Ectopic expression of GAS5 in multiple CRC cell lines resulted in an increase in apoptosis, a reduction in the rate of proliferation and inhibition of cell cycle progression. Conversely, downregulation of GAS5 inhibited apoptosis, and increased proliferation and cell cycle progression.

In conclusion, the results of the present study indicate that GAS5 negatively regulates the survival of CRC cells, and functions as a tumor suppressor by regulating cell growth and apoptosis, which is consistent with the results of previous studies performed in lymphoid cells and other epithelial cell lines $(10,11,37,38)$. However, the mechanisms underlying the effects of GAS5 in CRC remain to be completely elucidated. The results of the present study suggest that GAS5 has a complex role in CRC development. Dysregulation of GAS5 may be an important diagnostic and prognostic marker in patients with CRC. An improved understanding of the GAS5-mediated pathogenesis and development of CRC may facilitate the development of lncRNA-directed cancer therapeutics.

\section{Acknowledgements}

The present study was supported by the National Natural Science Foundation (grant nos. 81372290 and 81372291), the National High Technology Research and Development Program of China (grant no. 2015AA020110), the Specialized Research Fund for the Doctoral Program of Higher
Education (grant no. 20130001120064), and the Peking University People's Hospital Research and Development Fund (grant no. RDC2013-17).

\section{References}

1. Stewart BW and Wild CP: World Cancer Report 2014. International Agency for Research on Cancer, Lyon, 2014.

2. Siegel R, Desantis C and Jemal A: Colorectal cancer statistics, 2014. CA Cancer J Clin 64: 104-117, 2014.

3. Papadopoulos V, Tsapakidis K, Riobo Del Galdo NA, Papandreou CN, Del Galdo F, Anthoney A, Sakellaridis N, Dimas K and Kamposioras K: The prognostic significance of the hedgehog signaling pathway in colorectal cancer. Clin Colorectal Cancer 15: 116-127, 2016.

4. Wang B, Shen ZL, Jiang KW, Zhao G, Wang CY, Yan YC, Yang Y, Zhang JZ, Shen C, Gao ZD, et al: MicroRNA-217 functions as a prognosis predictor and inhibits colorectal cancer cell proliferation and invasion via an AEG-1 dependent mechanism. BMC Cancer 15: 437, 2015.

5. De Roock W, De Vriendt V, Normanno N, Ciardiello F and Tejpar S: KRAS, BRAF, PIK3CA, and PTEN mutations: Implications for targeted therapies in metastatic colorectal cancer. Lancet Oncol 12: 594-603, 2011.

6. Wang KC and Chang HY: Molecular mechanisms of long noncoding RNAs. Mol Cell 43: 904-914, 2011.

7. Zhang X, Gejman R, Mahta A, Zhong Y, Rice KA, Zhou Y, Cheunsuchon P, Louis DN and Klibanski A: Maternally expressed gene 3, an imprinted noncoding RNA gene, is associated with meningioma pathogenesis and progression. Cancer Res 70: 2350-2358, 2010.

8. Gutschner T and Diederichs S: The hallmarks of cancer: A long non-coding RNA point of view. RNA Biol 9: 703-719, 2012.

9. Prensner JR and Chinnaiyan AM: The emergence of lncRNAs in cancer biology. Cancer Discov 1: 391-407, 2011.

10. Mourtada-Maarabouni M, Hedge VL, Kirkham L, Farzaneh F and Williams GT: Growth arrest in human T-cells is controlled by the non-coding RNA growth-arrest-specific transcript 5 (GAS5). J Cell Sci 121: 939-946, 2008.

11. Mourtada-Maarabouni M, Pickard MR, Hedge VL, Farzaneh F and Williams GT: GAS5, a non-protein-coding RNA, controls apoptosis and is downregulated in breast cancer. Oncogene 28: 195-208, 2009.

12. Edge SB and Compton CC: The American Joint Committee on Cancer: The 7th edition of the AJCC cancer staging manual and the future of TNM. Ann Surg Oncol 17: 1471-1474, 2010. 
13. Livak KJ and Schmittgen TD: Analysis of relative gene expression data using real-time quantitative PCR and the 2(-Delta Delta C(T)) Method. Methods 25: 402-408, 2001.

14. Gibb EA, Vucic EA, Enfield KS, Stewart GL, Lonergan KM, Kennett JY, Becker-Santos DD, MacAulay CE, Lam S, Brown CJ and Lam WL: Human cancer long non-coding RNA transcriptomes. PLoS One 6: e25915, 2011.

15. Park JY, Lee JE, Park JB, Yoo H, Lee SH and Kim JH: Roles of Long Non-Coding RNAs on tumorigenesis and glioma development. Brain Tumor Res Treat 2: 1-6, 2014.

16. Mercer TR, Dinger ME and Mattick JS: Long non-coding RNAs: Insights into functions. Nat Rev Genet 10: 155-159, 2009.

17. Wilusz JE, Sunwoo H and Spector DL: Long noncoding RNAs: Functional surprises from the RNA world. Genes Dev 23: 1494-1504, 2009.

18. Michalik KM, You X, Manavski Y, Doddaballapur A, Zörnig M, Braun T, John D, Ponomareva Y, Chen W, Uchida S, et al: Long noncoding RNA MALAT1 regulates endothelial cell function and vessel growth. Circ Res 114: 1389-1397, 2014

19. Zhang EB, Yin DD, Sun M, Kong R, Liu XH, You LH, Han L, Xia R, Wang KM, Yang JS, et al: P53-regulated long non-coding RNA TUG1 affects cell proliferation in human non-small cell lung cancer, partly through epigenetically regulating HOXB7 expression. Cell Death Dis 5: e1243, 2014.

20. Gupta RA, Shah N, Wang KC, Kim J, Horlings HM, Wong DJ, Tsai MC, Hung T, Argani P, Rinn JL, et al: Long non-coding RNA HOTAIR reprograms chromatin state to promote cancer metastasis. Nature 464: 1071-1076, 2010.

21. Tripathi V, Ellis JD, Shen Z, Song DY, Pan Q, Watt AT, Freier SM Bennett CF, Sharma A, Bubulya PA, et al: The nuclear-retained noncoding RNA MALAT1 regulates alternative splicing by modulating SR splicing factor phosphorylation. Mol Cell 39: 925-938, 2010

22. Nie Y, Liu X, Qu S, Song E, Zou H and Gong C: Long non-coding RNA HOTAIR is an independent prognostic marker for nasopharyngeal carcinoma progression and survival. Cancer Sci 104: 458-464, 2013

23. Zhou Y, Zhang X and Klibanski A: MEG3 noncoding RNA: A tumor suppressor. J Mol Endocrinol 48: R45-R53, 2012.

24. Niinuma T, Suzuki $H$, Nojima $M$, Nosho $K$, Yamamoto $H$, Takamaru H, Yamamoto E, Maruyama R, Nobuoka T, Miyazaki Y, et al: Upregulation of miR-196a and HOTAIR drive malignant character in gastrointestinal stromal tumors. Cancer Res 72: 1126-1136, 2012.

25. Kotake Y, Nakagawa T, Kitagawa K, Suzuki S, Liu N, Kitagawa M and Xiong Y: Long non-coding RNA ANRIL is required for the PRC2 recruitment to and silencing of p15(INK4B) tumor suppressor gene. Oncogene 30: 1956-1962, 2011.

26. Khalil AM, Guttman M, Huarte M, Garber M, Raj A, Rivea Morales D, Thomas K, Presser A, Bernstein BE, van Oudenaarden A, et al: Many human large intergenic noncoding RNAs associate with chromatin-modifying complexes and affect gene expression. Proc Natl Acad Sci USA 106: 11667-11672, 2009.
27. Smith CM and Steitz JA: Classification of gas5 as a multi-small-nucleolar-RNA (snoRNA) host gene and a member of the 5'-terminal oligopyrimidine gene family reveals common features of snoRNA host genes. Mol Cell Biol 18: 6897-6909, 1998.

28. Muller AJ, Chatterjee S, Teresky A and Levine AJ: The gas5 gene is disrupted by a frameshift mutation within its longest open reading frame in several inbred mouse strains and maps to murine chromosome 1. Mamm Genome 9: 773-774, 1998.

29. Schneider C, King RM and Philipson L: Genes specifically expressed at growth arrest of mammalian cells. Cell 54: 787-793, 1988.

30. Renganathan A, Kresoja-Rakic J, Echeverry N, Ziltener G, Vrugt B, Opitz I, Stahel RA and Felley-Bosco E: GAS5 long non-coding RNA in malignant pleural mesothelioma. Mol Cancer 13: 119, 2014

31. Lodygin D, Tarasov V, Epanchintsev A, Berking C, Knyazeva T, Körner H, Knyazev P, Diebold J and Hermeking H: Inactivation of miR-34a by aberrant $\mathrm{CpG}$ methylation in multiple types of cancer. Cell cycle 7: 2591-2600, 2008.

32. Pickard MR, Mourtada-Maarabouni M and Williams GT: Long non-coding RNA GAS5 regulates apoptosis in prostate cancer cell lines. Biochim Biophys Acta 1832: 1613-1623, 2013.

33. Yacqub-Usman K, Pickard MR and Williams GT: Reciprocal regulation of GAS5 lncRNA levels and mTOR inhibitor action in prostate cancer cells. Prostate 75: 693-705, 2015.

34. Sun M, Jin FY, Xia R, Kong R, Li JH, Xu TP, Liu YW, Zhang EB, Liu XH and De W: Decreased expression of long noncoding RNA GAS5 indicates a poor prognosis and promotes cell proliferation in gastric cancer. BMC Cancer 14: 319, 2014.

35. Cao S, Liu W, Li F, Zhao W and Qin C: Decreased expression of IncRNA GAS5 predicts a poor prognosis in cervical cancer. Int J Clin Exp Pathol 7: 6776-6783, 2014.

36. Gee HE, Buffa FM, Camps C, Ramachandran A, Leek R, Taylor M, Patil M, Sheldon H, Betts G, Homer J, et al: The small-nucleolar RNAs commonly used for microRNA normalisation correlate with tumour pathology and prognosis. Br J Cancer 104: 1168-1177, 2011.

37. Mourtada-Maarabouni M, Hasan AM, Farzaneh F and Williams GT: Inhibition of human T-cell proliferation by mammalian target of rapamycin (mTOR) antagonists requires noncoding RNA growth-arrest-specific transcript 5 (GAS5). Mol Pharmacol 78: 19-28, 2010.

38. Kino T, Hurt DE, Ichijo T, Nader $\mathrm{N}$ and Chrousos GP: Noncoding RNA gas 5 is a growth arrest- and starvation-associated repressor of the glucocorticoid receptor. Sci Signal 3: ra8, 2010. 